\title{
Application of EHD-enhanced drying technology: a sustainable approach for Vietnam's agricultural product processing in the future
}

\author{
Úng dụng công nghệ sấy cải tiến EHD nhằm phát triển bền vũng các quá trình \\ sấy khô nông sản tại Việt Nam trong tuoong lai \\ Review paper
}

Vu, Anh Tuan ${ }^{*}$; Do, Thi Tam ${ }^{1}$; Vu, Anh Ngoc ${ }^{2}$; Pham, Van Lang ${ }^{3}$; Lai, Feng Chuan

${ }^{I}$ Mechanical Engineering Faculty, Thai Nguyen University of Technology, Highway 3, Thai Nguyen, Vietnam; ${ }^{2}$ International Training Faculty, Thai Nguyen University of Technology, Highway 3, Thai Nguyen, Vietnam, ${ }^{3}$ Vietnam Institute of Agricultural Engineering and Post-Harvest Technology, Cau Giay, Ha Noi, Vietnam; ${ }^{4}$ School of Aerospace and Mechanical Engineering, University of Oklahoma, 865 Asp. Avenue, Felgar Hall 218A, Norman, OK 73019-1052, USA

\begin{abstract}
Drying contributes a significantly important role in processing of agricultural products in Vietnam, particularly for high-value agricultural exports. Conventionally thermal-based drying techniques have remained critical disadvantages in term of enhancing product quality and process efficiency. The typical disadvantages include deterioration of organoleptic and nutritional properties, highenergy consumption, expensive costs yet low efficiency and hazards to environment change due to the consumption of fossil fuel sources. Electrohydrodynamics (EHD) drying technology has been demonstrated as an innovative solution for drying enhancement in various applications. This paper aims at an overview of the state-of-the-art EHD drying technology to enhance heat and mass transfer in agricultural drying processes. A case study is then presented to demonstrate an even better process efficiency, compared to the state-of-the-art EHD drying technology, and to shorten the gap "research-to-market". Finally, this study shows obviously potential applications of this innovative technology in sustainable development of food and post-harvesting agricultural processing for Vietnam in the future.
\end{abstract}

Sấy khô đóng một vai trò quan trọng trong việc chế biến và bảo quản nông sản sau thu hoạch tại Việt Nam, đặc biệt đối với các mặt hàng nông sản cao cấp phuc vu xuất khẩu. Các phuong pháp sấy khô bằng nhiệt truyền thống tồn tại nhiều nhwợc điểm trong việc nâng cao hiệu quả sấy và bảo đảm chất lựng nông sản. Những nhược điểm nổi bật bao gồm: biến đổi thành phần hóa học và giảm giá trị dinh duõng của nông sản sau sấy do sủ dụng nhiệt trong quá trình sấy, tiêu hao nhiên liệu lớn, chi phí nhiên liệu, lắp đặt và duy trì hệ thống sấy cao nhung hiệu suất thấp và đặc biệt ảnh hưởng tới môi truờng do sủ dụng các nguồn nhiên liệu hóa thạch. Công nghệ sấy cải tiến khiđiện động lực học (EHD) hiện tại đã cho thấy tiềm năng thay thế các phuơng pháp sấy truyền thống. Bài báo tập trung giới thiệu co chế sấy các sản phẩm nông sản bằng công nghệ EHD; qua đó tác giả giới thiệu một mô hình sấy đã chế tạo thành công cho hiệu quả thậm chí còn cao hơn các mô hình hiện tại, đồng thời dễ dàng triển khai trong ngành công nghiệp sấy khô nông sản. Nghiên cưu này chỉ ra tiềm năng úng dụng to lớn của công nghệ EHD trong phát triển bền vũng các quá trình sấy khô nông sản cao cấp tại Việt Nam trong tuoong lai.

Keywords: ElectroHydroDynamics (EHD), drying, corona wind, efficiency, agricultural products, sustainable development 


\section{Introduction}

According to recent report in 2013 (Macdonald, 2013), the Vietnamese agricultural sector was worth 36.8 Billion USD in 2011, representing $21.6 \%$ of GDP, where agriculture's share of exports has taken over a significant importance over past 20 years (Table 1). Agriculture, forestry and fisheries together employ $47.4 \%$ of the Vietnamese population, with the majority of agricultural production taking place on family farms of less than 0.5 ha each. For example, rice and coffee are Vietnam's largest exports, followed by pepper, starches, cassava, rubber and seafood. "In volume terms, in 2011 was the biggest exporter of shelled cashew nuts and pepper and the second biggest of rice, green coffee, and several other products". In order to increasing competitiveness of the country's agricultural exports, Vietnam has successfully concentrated on increasing production by significantly investing on technology development of agricultural production since the 1990s. However, this has come at the expense of quality, biodiversity, polluted water supply, and degraded soil and environment. Vietnamese agricultural products are generally low quality and there are justifiable domestic and international concerns about food safety due to lack of regulation and lax oversight of existing standards.

In order to strengthen the competitiveness of agricultural exports, together with shortening the link in the marketing channel between the farmer and the ultimate consumers, food processing and agricultural postharvest storage have received a broad investment and development and contribute a large and rapidly growing industry in Vietnam. Among all post-harvesting technologies, drying is one of the oldest methods but the most effective way, widely used in Vietnam for preserving various agricultural products. Importantly, drying processes contribute a significant role in the post-harvesting process chain for almost all advanced quality-required products to export; therefore, this process considerably promises a precious benefit to Vietnam's economy.

Regardless of various thermal-based methods in agricultural product preservation, conventional drying techniques are associated with convective, conductive, radiative, and dielectric heating, as well as drying in superheated steam and lyophilization either alone or in various combination
(Bajgai et al., 2006). However, utilization of high amount of energy in drying industry makes those aforementioned drying techniques one of the most energy-intensive operations, and therefore highly expensive costs. Furthermore, those drying methods produce significantly undesired changes in the physical, chemical, and biological properties of food; consequently, the thermal-based drying processes result in a great loss of texture, colour, and volatiles in agricultural products. To avoid heat involvement during processing, freeze-drying technique was introduced which provided dehydrated products of distinguished sensory quality. Nevertheless, expensive cost process was the major limit of this application at the commercial scale. Along with the strategy to reduce heat generation during the drying processes, osmotic drying can be performed at lower temperature; however, high drying time mainly causes low process efficiency.

In addition, further approach in developing drying system for sustainability is a reduction of energy usage, which is in turns of less greenhouse gas (GHG) emission. Thus, the existing thermal-based heating dryers which generate heat by burning fossil fuel sources require extreme evaluations of energy performance and efficiency. Apart from energy aspects, intensive demands arising from food market, particularly the superior standards of product quality from US. and Europe, bring an extreme challenge to Vietnam's export industries. High quality requirements of agricultural products with naturally maintained colour and a full complement of flavours and nutrients thread the export share of Vietnam's food processing industry. In conclusion, to increase competitiveness in the international market of agricultural product export, the domestic enterprises of Vietnam have to entirely solve following interdisciplinary requirements: high product quality, low energy consumption, high production rate, and environmentfriendly food processing. Solutions for an innovative drying technology turn out a sustainable development for the Vietnam's food processing industry.

In Vietnam, present drying processes of agricultural products are mainly conventionally solar-based and hot airgenerated methods. The latter often causes heat damage and adversely affects texture, colour, flavour, and the nutritional value of dried products. Since the material to be dried only absorbs a fraction of the energy conveyed

Table 1. Contribution of agriculture, forestry and fisheries to export

\begin{tabular}{cccccc}
\hline Year & Total exports & $\begin{array}{c}\text { Export of agriculture, forestry } \\
\text { and fisheries' products }\end{array}$ & $\begin{array}{c}\text { Export of rice, coffee, seafood, fruits, } \\
\text { and vegetables }\end{array}$ \\
\cline { 2 - 5 } & million US\$ & million US\$ & \% of total exports & million US\$ & $\%$ of total exports \\
\hline 1991 & 2,087 & 1,090 & $52.2 \%$ & 629 & $30.1 \%$ \\
1992 & 2,581 & 1,276 & $49.4 \%$ & 849 & $32.9 \%$ \\
1993 & 2,985 & 1,444 & $48.4 \%$ & 923 & $30.9 \%$ \\
1994 & 4,054 & 1,905 & $47.0 \%$ & 1,327 & $32.7 \%$ \\
1995 & 5,449 & 2,521 & $46.3 \%$ & 1,806 & $33.1 \%$ \\
1996 & 7,260 & 3,051 & $42.0 \%$ & 1,954 & $26.9 \%$ \\
1997 & 8,700 & 3,200 & $36.8 \%$ & 2,204 & $25.3 \%$ \\
\hline Annual growth & $\mathbf{2 6 . 9 \%}$ & $\mathbf{1 9 . 7 \%}$ & & $\mathbf{2 3 . 2 \%}$ & \\
\hline
\end{tabular}

(Source: Ministry of Planning \& Investment) 
by air or generated by heat exchanger, these techniques are normally low in the efficiency of energy utilization. Solar drying systems do not need special equipment and technology, and neither does it incur high expenses; however, its application is limited to the contamination with dust, soil, sand particles and insects, and difficulty-tocontrol process. As a result, the product quality is often poor. In response to the disadvantages of conventional drying processes, there has been considerably growing interests in non-thermal processing of food and similar materials as well as environment friendly.

During last decades, Electrohydrodynamics (EHD) has widely been investigated in a broad range of engineering areas for enhancement of heat and mass transfer. The process itself poses significantly low energy consumption; in addition, the mass and heat transfer is enhanced by a clean and non-thermal process. According to those advantageous benefits, this state-of-the-art technology turns out a significant potential for a sustainable development of future's drying processes which demand an interdisciplinary requirements of green and clean environment, low energy consumption for cost efficiency, and guarantee of remaining beneficial physiochemical properties, i.e. nutrient content, flavour, shrinkage and colour. Yet, up to now, there have been only few researches on EHD technology in food drying application.

This paper aims at an overview of the EHD-based drying technology, which provides a great potential for a wide range of bulk and industrial applications of agricultural products in Vietnam. Based on the introduction of process fundamentals and experimental set-up, a case study presents successful results and outcomes in the development of an innovative drying method for Vietnam's high quality agricultural products to export.

\section{EHD-enhanced heat and mass transfer process}

Drying is defined as a process of moisture removal due to simultaneous heat and mass transfer. It is general understanding that a thin layer of relatively inert air exists on the surface of water when air flows over a body of water. This saturated air layer interferes with diffusion of water molecules from water surface to the bulk airflow. As the air velocity over the surface reduces thickness of saturated air layer increases and evaporation rate degrades, so any method that can disturb this boundary layer might improve evaporation rate (Karami et al., 2011).

Electrohydrodynamics (EHD) can substantially enhance water evaporation. The primary mechanism involved in EHD process is the generation of a secondary airflow, which is commonly known as corona wind or ionic wind, by applying high voltage to an electrode with a small radius of curvature (Figure 1). The EHD-induced secondary flow when a high-intensity electric field is applied to ambient air can be thought of as a micro-jet of fluid issued from the charged electrode to the grounded surface.

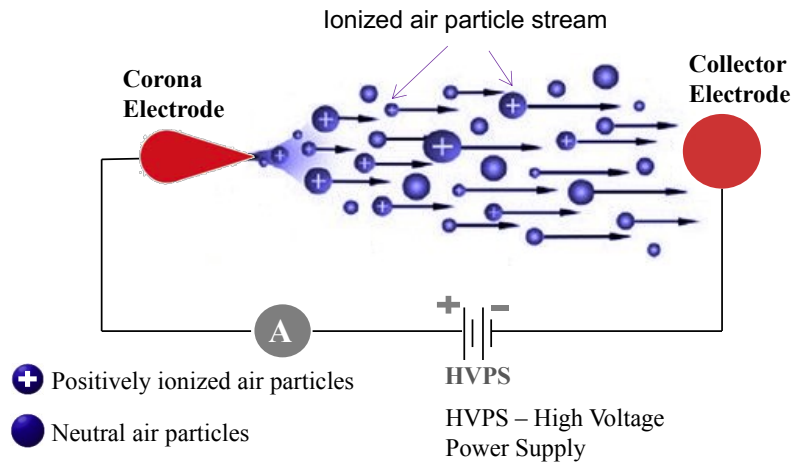

Figure 1. Corona principle in electrohydrodynamics

The net effect of this secondary flow is additional mixing of fluids and destabilization of boundary layer developed from the grounded surface on which the biological material is placed, therefore leading to a substantial increase in the mass transfer between the biological surface and the ambient air. Accordingly, several significant benefits of the EHD drying system can be pointed out against the conventional drying methods, which are definitely satisfied, the arising demands from food consumers. Firstly, the corona wind used to enhance mass transfer is generated at the room temperature and atmospheric pressure. Therefore, against to conventional processes wherein high airflows at the elevated temperatures are used, this processing condition makes it considerably attractive for low temperature applications. Also, the obvious advantage of EHD drying is its simple design, with no moving parts and no wear and tear. In addition, by taking place at room temperature, the EHD drying is considered a non-thermal food processing technique, which ensures the quality of food dehydration without any risk of flavour degradation, surface tarnishing or formation of an internal moisture gradient. Apart from guaranteed food quality, it is noticed that significantly low energy consumption of the EHD technique has been proven in previous research (Lai and Wong, 2003). Finally, the drying process, which is mainly based on corona wind energy and carried out in an isolated air container, promises clean conditions for food quality and environment-friendly.

\subsection{EHD-enhanced drying mechanism}

The primary requirement for a functional EHD drying system is generation of corona wind, which is done by air ions accelerated under a high intensity of electric field. As illustrated in Figure 1, the ionized air particles, bound together as a cloud of molecules by the Coulomb force, collide with neutral air particles and transfer their momentum, which in turn generates ionic wind. The corona wind then impinges on the moist biological material and influences on the saturated air layer, resulting in an evaporation enhancement (Figure 2; Go, 2013). As a consequence, water molecules orient themselves along the electric field direction and vaporize, leading to moisture loss. This process causes a lowering of entropy, which in turn lower temperature of the biological material being dried. Thus, the drying process itself can be escaped from heat and therefore is highly suitable for heat-sensitive materials. 


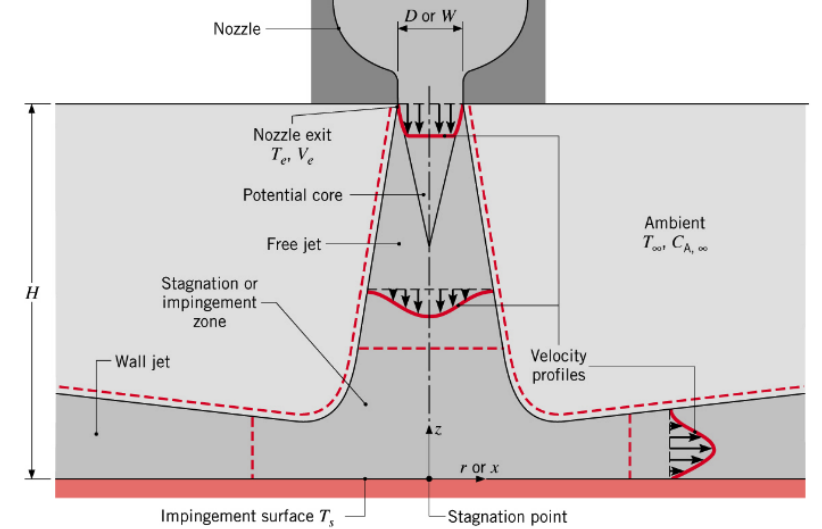

Figure 2. Schematic of heat transfer by an impinging jet (Source: Go, 2013)

The major mechanism of the EHD drying techniques to enhance heat and mass transfer lies on the strength of electric wind generated. This EHD enhancement performance is an active form of heat transfer augmentation that utilizes the effect of electrically induced secondary motions produced when a high voltage, low current electric field is applied to a dielectric fluid medium. During the EHD drying process, interaction of charges is rather complex under the influence of a strong electric field with three different states and consequently different dielectric properties of gas, liquid water and dried matter of solid biological material. Hence, the mathematical representation to describe this phenomenon is based on the electric body force on a volume basis $F$ as shown in equation 1 .

$$
F=q_{e} E-\frac{1}{2} E^{2} \nabla e_{0}+\frac{1}{2} \nabla\left[E^{2} \rho_{m}\left(d e_{0} / d \rho_{m}\right)\right]
$$

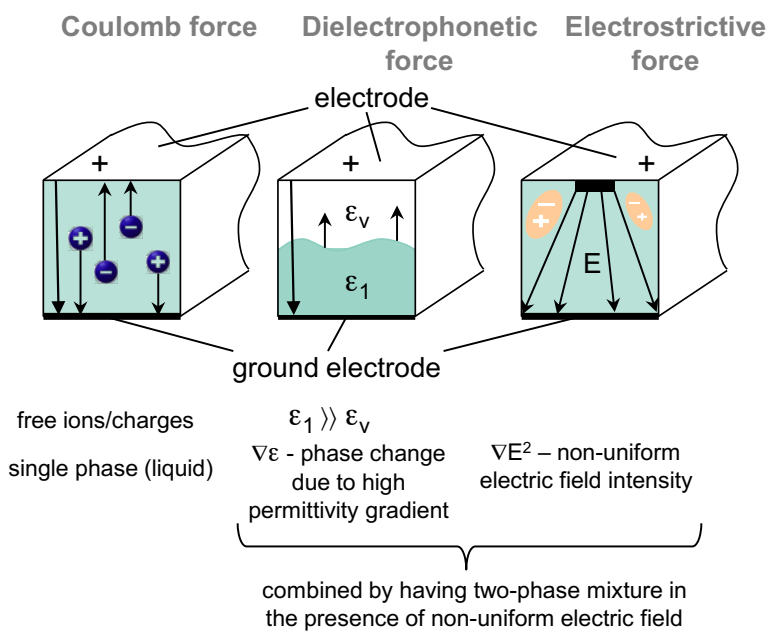

Figure 3. EHD body force on a volume basis

As illustrated in Figure 3, the electric body force can be split into three distinctive forces: the Coulomb force, the dielectrophoretic force, and the electrostrictive force. The first term of equation 1 represents the Coulomb force acting on the ionized particles, with which $E$ is the electric field strength $\left(\mathrm{V} . \mathrm{m}^{-1}\right)$ and $q_{e}$ is the charged density of ions $\left(\mathrm{C} . \mathrm{m}^{-3}\right)$. In a single-phase flow, the Coulomb force is the dominant contributor to the EHD body force and the resulting heat transfer enhancements. The second term describes the dielectrophoretic force, which arises from the spatial change of dielectric permittivity within the fluid medium. The electrostrictive force, referred in the third term, is associated with the inhomogeneity in the applied electric field, the density gradients, and the resulting changes in $\varepsilon$. The $\rho_{m}$ in this term is the mass density of air $\left(\mathrm{kg} . \mathrm{m}^{-3}\right)$ and $e_{0}$ is the medium permittivity $\left(\mathrm{F}^{\mathrm{m}} \mathrm{m}^{-1}\right)$. The second and third terms represent the polarization forces, created when pairs of charges transmit the electric force to the medium. For EHD-enhanced water evaporation, the Coulomb force remains the main driving force, whilst the polarization forces have a small but not necessarily negligible effect on the results.

Aforementioned, EHD drying performance depends on the strength of the corona wind, which impinges on the biological material being dried, then generates turbulent, vortex-like motions and enhances the mass transfer rates of the liquid and volatile components. The corona wind strength, i.e. the wind velocity $\left(v, \mathrm{~m} . \mathrm{s}^{-1}\right)$, can be derived from the electric field as following relationship (Equation 2), according to (Hashinaga et al., 1999):

$$
v=\left(e_{0} / \rho_{m}\right)^{1 / 2} \cdot E
$$

Based on brief fundamental introduction of the state-ofthe-art EHD drying technology as above, the following mainly focuses on built-up EHD-enhanced drying system as well as process efficiency.

\subsection{EHD-enhanced drying apparatus set-up}

A schematic diagram of biological material drying system is shown in Figure 4. In general, the equipment and instruments used in EHD-enhanced drying experiments include a high voltage power supply HVPS, digital balances, a temperature/humidity data logger, a van velocimeter, and a digital multimeter.

The high voltage power supply HVPS is primary device used to provide corona wind for any EHD drying system, whereby high voltage, generally required up to $30 \mathrm{kV}$, is applied to electrodes. Digital balances are used to measure the weight loss of water from both containers and are set up to communicate with a personal computer, with which data recorded by the digital balances during the experiments can be collected and stored for further analysis. Both temperature and humidity are measured by the temperature/humidity data logger with its internal sensors; besides, airflow velocity is measured by a van velocimeter. All devices are highly required relevant accuracy and capability range.

\subsection{Efficiency of EHD-enhanced drying}

This section aims at an evaluation of EHD drying efficiency throughout comparisons between conventional drying methods and the state-of-the-art EHD technology. Also, to encourage establishment of the EHD drying 
Table 2. Specifications of static convective rice drying ovens currently used in Vietnam

\begin{tabular}{lcccccc}
\hline \multirow{2}{*}{ Technical terms } & \multicolumn{2}{c}{ Vertically static convective ovens } & \multicolumn{3}{c}{ Flatbed convective ovens } \\
\cline { 2 - 6 } & STN-1,0 & STN-1,5 & STN-2,0 & STN-04 & STN-10 & STN-15* \\
\hline $\begin{array}{l}\text { Efficiency } \\
\text { (ton/batch) }\end{array}$ & 1.0 & 1.5 & 2.0 & 4 & 10 & 15 \\
$\begin{array}{l}\text { Capacity } \\
\text { (kW) }\end{array}$ & 1.1 & 1.5 & 2.0 & 4.5 & 11 & 15 \\
Coal consumption & $4 \div 5$ & $5 \div 6$ & $7 \div 8$ & $8 \div 10$ & $20 \div 25$ & $27 \div 30$ \\
(kg/hour) & 117,230 & 146,538 & 205,153 & 234,461 & 586,152 & 791,305 \\
$\begin{array}{l}\text { Energy conversion } \\
\text { (kJ/hour) }\end{array}$ & $\div 146,538$ & $\div 175,846$ & $\div 234,461$ & $\div 293,076$ & $\div 732,690$ & $\div 879,228$ \\
\hline
\end{tabular}

${ }^{*} \mathrm{STN}$ - is denoted for the drying machine associated with its capacity

Source: Vietnam Institute of Agricultural Engineering and Post-Harvest Technology

technology in the sustainable development in Vietnam for drying agricultural products, the authors mainly focus on current drying techniques in food processing in Vietnam; with which a review of EHD efficiency in agricultural and food drying systems are shown to prove the technology's benefits.

Table 2 provides current efficiency of various rice drying techniques in Vietnam. Humidity of dried rice by using these technologies can be reduced from $40 \%$ to $12 \%$ with hot-air of $50^{\circ} \mathrm{C}$ temperature. Obviously, according to these conventional drying techniques, the efficiency and therefore productivity can be increased with increasing the system capacity. However, extreme amount of energy consumed, large space required for machine establishment and difficult-to-control drying process pose considerable challenges for further applications in Vietnam.

Compared to energy estimation by conventional drying methods, Table 3 illustrates efficiency of another widely used-drying method, namely the sprouted bed dryer, for other agricultural products by summarizing the specific energy consumption (kJ/kg water) (Elizabeth et al., 2006).

Table 3. Energy consumption of bed-dryers

\begin{tabular}{lc}
\hline \multirow{2}{*}{ Products being dried } & Specific energy consumption \\
\cline { 2 - 2 } & $(\mathrm{kJ} / \mathrm{kg})$ \\
\hline Wheat & $3,360 \div 7,683$ \\
Corn electrode & $3,290 \div 3,535$ \\
Paprika & $4,091 \div 6,158$ \\
Potato pulp & 3,025 \\
Brewery yeast & $3,000 \div 3,500$ \\
\hline
\end{tabular}

In order to prove the significantly increasing efficiency of the EHD drying process, this paper's ambition is to present some authors' previous research results conducting to examine the application of EHD in enhancement of evaporation processes in drying. Series of experiments has been conducted in previous authors' work (Lai et al., $2002,2004,2005)$ to investigate the effect of corona discharge on the overall drying rate and to optimize drying as a function of electric field parameters, including electrode geometries such as wire electrode, single and multiple needle electrodes, discharge polarity and gap between electrodes. Based on the results from these research works

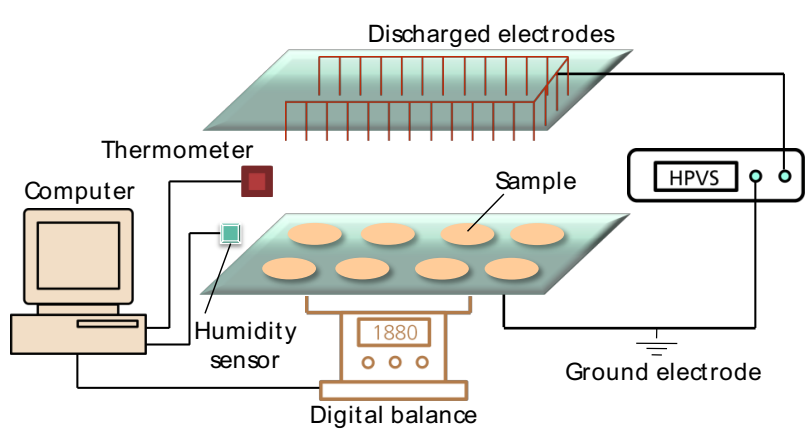

Figure 4. Schematic of EHD drying experimental set-up

amount of specific energy consumed to evaporate one kilogram of water $(\mathrm{kJ} / \mathrm{kg})$ is illustrated in Figure 5 . It can be clearly seen that increasing energy required is together with an increase of applied voltage; therefore, the best performance is obtained at lower applied voltage. Also, the positive corona discharge provides slightly better performance than negative one at lower applied voltage. In terms of electrode gap, it is observed that the highest drying rate is achieved at smallest electrode gap; however, threshold applied voltage must be guaranteed to avoid arcs (Lai and Wong, 2003). Moreover, because increasing applied voltage brings an increase of energy consumption when using wire electrode, needle electrode is suggested for better performance at the voltage range from $15-20 \mathrm{kV}$ compared to wire electrode. So, what happens if multiple electrodes are used? As shown in Table 4 after summarizing works done (Lai and Sharma, 2005; Zheng et al., 2001), it can be concluded that the performance of multiple needle electrodes is better than wire and single electrode-based drying systems. Clearly, compared to Table 2 and Table 3 when conventional drying techniques are used, significantly low energy consumption is achieved by using EHD drying methods as well as low electric

Table 4. Summary of energy consumption among EHD drying models with different electrode types

\begin{tabular}{lc}
\hline \multicolumn{1}{c}{ EHD drying models with different electrode types } \\
\cline { 2 - 2 } EHing model & Energy consumption \\
\hline Single needle electrode & $100 \div 1,250$ \\
Multiple needle electrode & $100 \div 800$ \\
Wire electrode & $200 \div 5,000$ \\
\hline
\end{tabular}


power. Also, it should be noticed that heat source for drying medium generated by coal, which is significantly harmful to the environment when burning and needs to be avoided, is widely used in the conventional drying techniques. Hence, the new EHD technology becomes a promising technique for the next generation of drying innovation because it strongly protects our environment and provides solution for sustainable development in Vietnam for future decades.

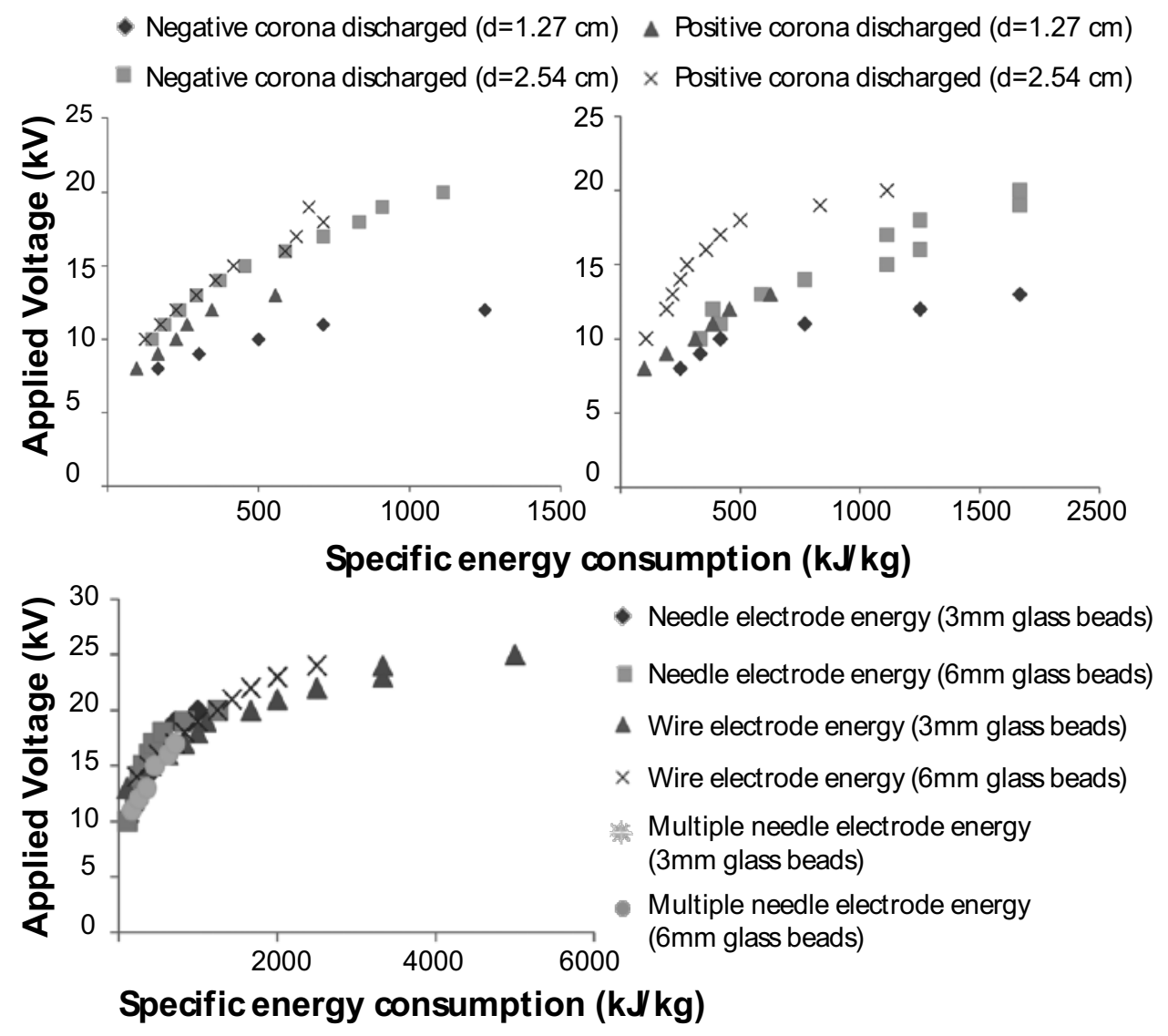

Figure 5. Energy consumption at various voltages for different electrode types

\section{Case study - prototype construction of the EHD-enhanced drying system}

Previous sections have clearly proven the outstanding efficiency of the EHD-enhanced drying with various agricultural materials; however, development of this technology has still been remained very much in the laboratory. In order to set foot on the realization of this technology toward industrial applications, this paper presents an EHD-enhanced drying prototype successfully designed in author's recent work as a case study. The primary objective of this introduction is to demonstrate that the precious efficiency of EHD technique can be scaled up from laboratory bench to meet a variety of demands in industry; also, the technology readiness is highly beneficial for Vietnam food processing and advanced agricultural product quality to export.

\subsection{Prototype configuration}

As shown in Figure 6, two belt-conveyors are set alongside each other and run in opposite directions, whereby the prototype allows agitating or mixing product sample to ensure that all parts of the sample are exposed to corona wind. Another objective of this design is to avoid manual work for continuous loading of the sample during operation. To do so, both conveyors are tilted at an angle of $11.5^{\circ}$, whereof gravity can be used as loading and mixing mechanism. Furthermore, a sample transfer device is constructed at one end of each conveyor to bridge the gap between two conveyors and to transport the sample from the top of one conveyor to the bottom of the other.

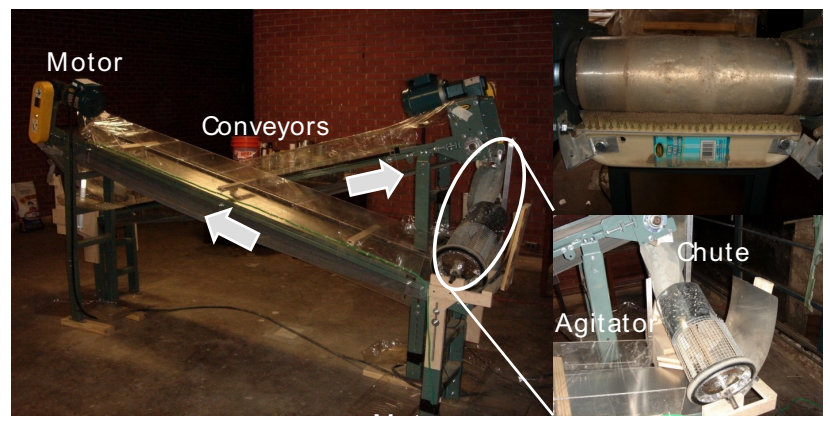

Figure 6. EHD-enhanced drying prototype

Wire electrodes are chosen when constructing this prototype to ensure that generated corona wind can cover a large area of the sample. The wire electrodes are suspended horizontally across the width of the conveyors. This design also allows adjusting electrodes' spacing and 
height. Finally, aluminium flashing is placed over the conveyors as the grounded surface to generate the corona effect.

\subsection{Material and experimental devices}

Construction sand was first used for the benefit of simplicity to evaluate the prototype performance. At the beginning of each run, water was slowly added to the sand, with which the amount of water added and the total mass of sand were recorded. Soil moisture sensor (ThetaProbe, ML2x by Delta-T Devices) was used to measure volumetric moisture content $\left(\theta_{v}\right)$. This measurement signal from the probe was visualized by moisture meter $(\mathrm{HH} 2$, Delta$\mathrm{T}$ Devices). The accuracy of the moisture sensor is $\pm 0.01 \mathrm{~m}^{3} / \mathrm{m}^{3}$ over a range between 0.05 and $0.6 \mathrm{~m}^{3} / \mathrm{m}^{3}$. The sand was loaded on the conveyor belt until a uniform thickness of $2 \mathrm{~cm}$. Spacing electrode was fixed at $5.08 \mathrm{~cm}$ with electrode height of $2.54 \mathrm{~cm}$. During experiments, change of ambient temperature is ensured to be minimal. Moisture variation was processed after every $5 \div 10$ minutes.

\subsection{Results and discussion}

Several experiments for drying damped sand have been carried out without and with different applied voltages for a better comparison. The moisture content variations are clearly shown in Figure 7. Obviously, moisture is almost linearly decreased in all cases with time. When no corona wind is generated, the drying rate within this EHD drying construction is observed to have a double performance increase compared to stationary design in previous work of authors (Balcer and Lai, 2004; Lai and Sharma, 2005). This observation can be explained by transitionally natural drying carried out by conveyors providing an effect similar to that of blow dry by cross flow. A smaller drying rate is observed compared to the case of no corona wind when a voltage of $7 \mathrm{kV}$ is applied. This situation can be recognized by too small corona wind effect because of low applied voltage; therefore, the corona wind effect is suppressed by cross flow, and even results in an adverse effect on drying performance. This explanation is strongly clear when higher voltages are applied, whereby drying rate of this prototype starts increasing. Comparison of drying rate performance at different applied voltage is more clearly observed when all cases are summed up in a diagram as illustrated in Figure 8. Qualitatively, the EHDdrying enhancement when a voltage of $12 \mathrm{kV}$ is applied is found to be 1.35 , which is defined as the drying rate with electric field and without; this performance enhancement is about three times better than the case of stationary drying system.
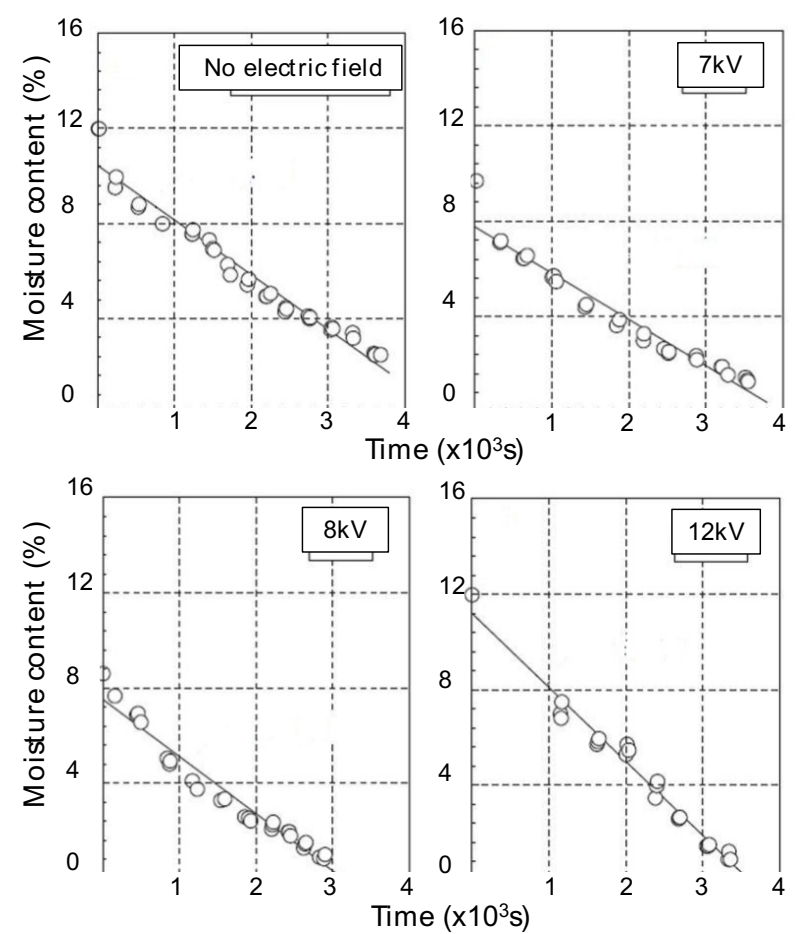

Figure 7. Moisture content drops at different applied voltages

\section{Conclusions and outlook}

According to significantly raising quality demands of food and agricultural products on the domestic and international markets to export, conventional drying methods for food processing and postharvest storage of agricultural products in Vietnam remain critical irrelevance, such as deterioration of organoleptic and nutritional properties. Other aspects in term of high energy consumption and thus expensive cost, remaining causes of environment change and low process efficiency strongly force researchers and industries to search for alternative technological solutions for drying heat-sensitive foods and agricultural products.

Occupying outstanding properties for enhancement of drying processes, EHD-based method turns out a promising alternative technology for a wide range of industrial applications. Significant advantages of thermal-free processing, extremely low energy consumption yet high efficiency and validity for various types of material geometries promises this innovative technology in supplying superior quality food products with high nutritional value, natural colour and textural characteristics. Against conventional drying methods, apart from energy efficiency, this technology ensures clean drying conditions for agricultural products and environment-friendly. Therefore, these overall superior advantages of this drying technology open a huge potential for sustainable development of food processing for agricultural export products of Vietnam in the future. 


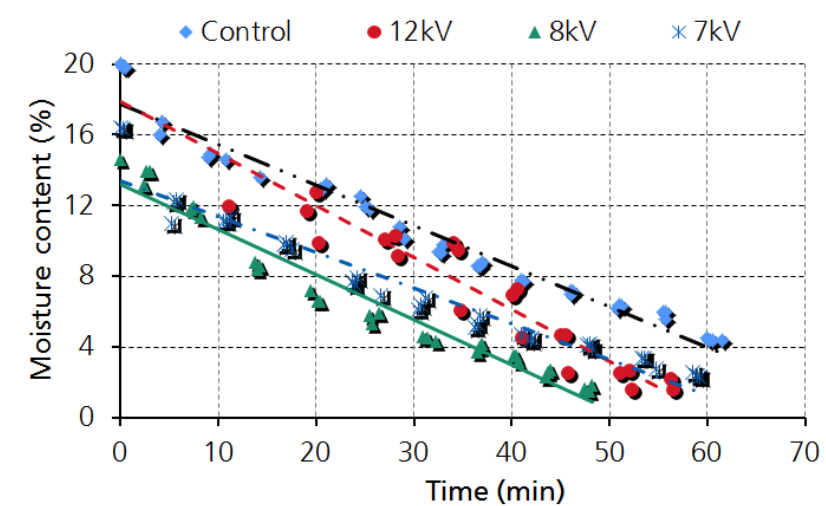

Figure 8. Comparison of moisture content drops

In addition, the prototype in this paper has not only demonstrated even a better enhancement in drying process but also shown a simple construction with extremely low costs for implementation and maintenance; it means the gap of "research-to-market" can be shortened. It is foreseeable that the industry of food and post-harvesting agricultural processing in Vietnam can achieve significant benefits when the advantageous ideas of the innovative technology can be quickly implemented to replace conventionally low efficient drying techniques. Technology success and high quality product supply will definitely increase the competitiveness and guarantee trademark of Vietnam's food processing enterprises in the intensive global market of food supply.

\section{References}

[1] Alem-Rajabi, A. and Lai, F.C. (2005) EHDenhanced drying of partially wetted glass beads. Drying Technology, Vol. 23(3), p.597-609.

[2] Bajgaia, T.R., Raghavana, G. S. V., Hashinagab F. and Ngadia, M.O. (2006) Electrohydrodynamic Drying - A Concise Overview, Drying Technology. Vol. 24(7), p.905-910.
[3] Balcer, B.E. and Lai, F.C. (2004) EHD-enhanced drying with multiple-wire electrode. Drying Technology, Vol. 22(4), p.821-836.

[4] Elizabeth, P., Tibor, S. and Arun, M. (2006) Spouted bed drying. In Handbook of Industrial Drying, 3rd ed.; CRC Press: Boca Raton, FL, p.453-488.

[5] Go, D.B. (2013) Lecture on Intermediate Heat Transfer, AME 60634, University of Notre Dame.

[6] Hashinaga, F., Bajgai, T.R., Isobe, S., and Barthakur, N.N. (1999) Electrohydrodynamic (EHD) drying of apple slices, Drying Technology, Vol. 17(3), p.479-495.

[7] Karami, R., Kamkari, B., and Kashefi, K. (2011) Investigation of Corona wind Effect on Heat and Mass Transfer Enhancement, World Academy of Science, Engineering and Technology. Vol. 5(10), p.444-450.

[8] Lai, F.C and Wong, D.S (2003) EHD-enhanced drying with needle electrode, Drying Technology. Vol. 21(7), p.1291-1306.

[9] Lai, F.C. and Lai, K.W. (2002) EHD-enhanced drying with wire electrode. Drying Technology, Vol. 20(7), p.1393-1405.

[10] Lai, F.C. and Sharma, R.K (2005) EHD-enhanced drying with multiple needle electrode. Journal of Electrostatics, Vol. 63(3-4), p.223-237.

[11] Macdonald, M., (2013) Trans-Pacific Partnership Trade Negotiations. Background: Agriculture in Vietnam. Queen's Institute on Trade Policy.

[12] Zheng, D.J., Cheng, Y.Q., Liu, H.J., and Li, L.T. (2011) Investigation of EHD-enhanced water evaporation and a novel empirical model. International Journal of Food Engineering, Vol. 7(2). 